\title{
Administrative Issues In Developing An Electron Microscopy Outreach Program
}

\author{
Betty Thompkins
}

Department of Pathology and Laboratory Medicine, Albert Einstein Medical Center, Philadelphia, Pennsylvania

There are many unique problems in designing an outreach program for high school students:

- Securing adequate fiscal support

- Determining whether to use an already existing facility or create a new one

- Defining institutional objectives

- Staffing issues

- Curriculum development

- Student Safety

Addressing infrastructural issues should be the first step in determining the appropriate level of needed fiscal support. Devise an architecturally sound plan that meets the needs and goals of the program. Identifying a suitable space is the most important aspect of creating an electron microscopy facility. Consult equipment representatives and your facilities management staff. It is likely that the in-house staff will have had very little experience with these types of equipment. However, company representatives will gladly provide you with the appropriate specifications.

Equipment should be the next consideration. Define and prioritize equipment needs. Contact potential vendors, local electron microscopy societies and grant agencies. Vendors will be helpful locating equipment and providing alternatives. Local electron microscopy societies will also be helpful in identifying potentially available equipment and supplies. Acquisition of supplies is best handled by contacting established microscopy supply companies. Furthermore, bartering is a valuable tool when approaching vendors.

Budget sharing should be addressed early and often with school officials. Once a working budget is in place, present each affiliate with a proposal indicating budget projections and designated goals. Naturally, there will be lots of negotiation; try to be flexible. Equipment upkeep is a huge part of budget sharing. Maintenance contracts are expensive. Sometimes, a less expensive arrangement can be reached. Bartering can be a valuable tool in this instance also.

Frequently, vendors will loan equipment to outreach programs. It is not necessary to have each piece of equipment under contract. Changing technology is a task that is best managed by staying in constant contact with vendors. They are always anxious to show off their latest technology.

When deciding whether or not to create a new facility or to use an existing one, company policy must be considered. Many companies have very rigid policies regarding site availability and equipment use. Consult department administration to create a handbook specifically designed for student users. By involving administration, one can be assured that legal and insurance issues will be addressed. If the decision is made to create a new facility on a school campus, select an institution with similar goals. 
In addition, establish a five-year academic plan that includes curriculum development, expansion and science fair participation. You may find that public schools have a greater interest than private (independent) schools. Public schools often do not have as many partnering opportunities and endowment options as do private schools.

Once an institution is selected, staffing and salary issues can be addressed. Many school districts have strict guidelines regarding teacher certification and union membership. In some states, there are "fast track" certification programs for non-certified personnel. This type of credential is not necessary in all states.

Unions are another issue that must be considered. Most teachers in this country are union members. Union exemptions are usually easier acquired in smaller communities. In the event that an exemption cannot be obtained, teaching staff may be forced to join the union and adopt union guidelines. These guidelines include salary requirements, class preparation time, certification requirements, dues, and other regulations. Also, these guidelines can often be accommodated without much ado. However, issues such as salary requirements can have significant budget impact.

Curriculum development is another area that should be evaluated very carefully. Decide the length of the program, student grade level, curriculum credit and class time (length, starting time). Some programs span more than one year so that a more complete curriculum can be offered. Once the length of the program is decided, grade levels can be assigned. For instance, if a multi-year program is decided upon, $10^{\text {th }}$ and $11^{\text {th }}$ graders may be the best candidates. If a single year program is selected, choosing $11^{\text {th }}$ or $12^{\text {th }}$ graders may be best. Curriculum credit is a topic that will need to be discussed with the Science Department Head and Principal.

Once the program is established and has a positive record of accomplishment, curriculum credit will be much easier to achieve. Determine the length of the class and the time that it is to be offered. If the class is to be offered as an elective, it must be scheduled during regular school hours. This is also the case if the teacher is a union member. After these matters are resolved, a complete syllabus can be prepared and distributed to all appropriate administration and department heads for review.

Moreover, student safety is a matter of utmost importance. If the decision is made to use an offschool campus facility, then secure student transportation may be a challenge. Identify transportation options and discuss them with school authorities and company administration. Choosing a class time that does not interfere with other student activities, in order to prevent scheduling conflicts. For instance, schedule class time for Saturday mornings from 8:00 AM to 10:30 AM.

Please note, there are new government guidelines that dictate the types and origins of specimens that students can work with. All prepared specimens should be labeled as anonymously as possible. Specimen confidentially is a huge issue particularly in a clinical setting.

Once these primary issues are addressed, many others will present themselves. Be flexible and open to alternatives. 